\title{
Pollination: Impact, role-players, interactions and study - A South African perspective
}

\section{AUTHORS: \\ Annemarie Gous ${ }^{1,2}$ (iD \\ Sandi Willows-Munro² (iD \\ Connal Eardley2,3 \\ Zacharias H. (Dirk) \\ Swanevelder $r^{1,4}$ iD}

\section{AFFILIATIONS:}

'Biotechnology Platform, Agricultural Research Council, Onderstepoort, Pretoria, South Africa

${ }^{2}$ School of Life Sciences, University of KwaZulu-Natal, Pietermaritzburg, South Africa ${ }^{3}$ Plant Protection Research Institute, Agricultural Research Council, Pretoria, South Africa ${ }^{4}$ College of Agriculture and Environmental Sciences, University of South Africa, Pretoria, South Africa

CORRESPONDENCE TO: Dirk Swanevelder

\section{EMAIL:}

swanevelderd@arc.agric.za

\section{DATES:}

Received: 24 Oct. 2016

Revised: 23 Jan. 2017

Accepted: 16 May 2017

\section{KEYWORDS:}

floral choice; bees; plantpollinator interactions; metabarcoding; pollen

\section{HOW TO CITE:}

Gous A, Willows-Munro S, Eardley C, Swanevelder ZH. Pollination: Impact, roleplayers, interactions and study - A South African perspective. S Afr J Sci. 2017;113(9/10), Art. \#2016-0303, 8 pages. http://dx.doi.org/10.17159/ sajs.2017/20160303

\section{ARTICLE INCLUDES: \\ $\times$ Supplementary material \\ $\times$ Data set}

\section{FUNDING:}

Belgian Directorate-General for Development Cooperation, Partim GTI; National Research Foundation (South Africa)
Plant-pollinator interactions are essential for maintaining both pollinator and plant communities in native and agricultural environments. Animal-instigated pollination can be complex. Plants are usually visited by a number of different animal species, which in turn may visit flowers of several plant species. Therefore, the identification of the pollen carried by flower visitors is an essential first step in pollination biology. The skill and time required to identify pollen based on structure and morphology has been a major stumbling block in this field. Advances in the genetic analysis of DNA, using DNA barcoding, extracted directly from pollen offers an innovative alternative to traditional methods of pollen identification. This technique, which is reviewed in detail, can be used on pollen loads sampled from bees in the field and from specimens in historic collections. Here the importance of pollination, the role-players involved, their management and the evolution of their interactions, behaviour and morphology are reviewed - with a special focus on South African bees.

\section{Significance:}

- Pollen metabarcoding will enable the identification of pollen for a multitude of uses, including agriculture, conservation and forensics.

- $\quad$ Plant-pollinator interaction documentation through pollen identification gives a more certain record of a visitor being a pollinator rather than a flower visitor that could be a nectar gatherer.

\section{Introduction}

South Africa has one of the world's most diverse landscapes, with high plant and pollinator diversity and endemism. ${ }^{1,2}$ Healthy plant-pollinator interactions are important to maintain both native plant and pollinator communities. The interactions between pollinators and their host plants are complex and very little is currently known about the floral choices of indigenous bees, specifically in South Africa. As a result of pressure from urban development, overexploitation of natural resources, and climate change, many of the nine biomes in South Africa are under threat. ${ }^{3}$ The effects of an anthropogenic influence on the environment dictates improved methods of studying plant-pollinator interactions, to understand how they may be influenced by environmental and ecological changes.

Most plant-pollinator interaction studies rely on lengthy field-based experiments. ${ }^{2}$ Observing pollinators in the field is not the only way to study their interactions with plants. Pollinator pollen load identification allows insight into the species' floral visits. Pollen loads provide a snapshot of the interactions with the plant community at the time they were caught. Bees (Hymenoptera: Apoidea) caught at a flower patch, for example, can have varying pollen loads because they can be either on their way to the flowers from the nest, or on their way from the flowers to the nest, or busy foraging at the patch. Neither identifying the pollen found on a sampled bee, nor netting a bee on a flower, can give definite answers regarding the plants it pollinates, and similarly, inferences on possible fruit and seed set cannot be made. ${ }^{4}$ Some pollination inferences can nonetheless be drawn, especially if multiple bee samples are investigated. Pollen loads sampled from pollinators could be identified by classic microscopic palynology or genetic methods. These two approaches are discussed in detail below.

Here, the role of pollination in agriculture and natural plant populations, with a special focus on bee pollination, is elucidated. The value of bee pollination in a South African context is reviewed and discussed, as is the potential impact that the introduction of a foreign bee species could have on highly diverse native bee populations. Advances in studying plant-pollinator interactions using genetic methods are also reviewed.

\section{The value of pollination}

Functional ecosystems require various essential ecosystem services to be performed. Ecosystem services are defined as services provided to humans by organisms that interact in the ecosystem and pollination is one such extremely important service. ${ }^{5}$ Plant-pollinator interaction is, in most instances, an intimate mutualistic relationship, in which both parties are reliant on each other for survival - plants for reproduction and pollinators for food or other forms of reward. Although a plant might have multiple pollinators, it is possible that one or more of these pollinators are specialists and may, therefore, rely heavily on that specific plant taxon for survival. ${ }^{6} \mathrm{~A}$ decline in the host plant numbers would ultimately lead to a decline in its specialist pollinators, and vice versa, with important impacts on maintaining biodiversity and ecosystems.

Pollination is extremely important, not only in natural ecosystems but also in artificial production environments. Biotic pollination of crops is important to consider from an agricultural production perspective because approximately one-third of all human food consumption results from animal-pollinated plants, of which up to $75 \%$ is used directly as food. ${ }^{6} \mathrm{~A}$ decline in crop pollinator populations would thus negatively impact crop production. The importance of pollinators has been illustrated in a study conducted on 137 single crops and five commodities, in which increases of $68.4 \%$ in production of the leading single crops and $71.6 \%$ in production of commodity crops were found with animal pollination. ${ }^{6}$ It was estimated that native insects in the United States of America (excluding the introduced honeybee) were solely responsible for USD3.07 billion worth of fruit and vegetable production in 2003. ${ }^{5}$ This figure clearly indicates the worth of indigenous pollinators to society for maximal crop production. 


\section{Plant-pollinator interactions}

Pollination is an important ecosystem service and often crucial for the survival of both parties involved, but is, in essence, an inadvertent process. From the view of the pollinator, it is not its specific goal to provide this service to its mutualistic plant partner, but it is rather a coincidental result of its actions while visiting these hosts. ${ }^{7}$ Bees, for example, can deliberately collect pollen, or pollen can passively adhere to bee bodies while they are visiting flowers. ${ }^{8}$ Mutualism between the plant and the pollinator is based on rewards (pollen, nectar and oil) that the pollinator receives from the plant, and the plant gains the service of successful pollination, thereby securing its reproductive success..$^{7-9}$ This mutualism can be facultative or obligate, depending on whether the plant is self-compatible or whether it is monoecious or dioecious. ${ }^{7}$ Parasitic interactions are also possible when a potential pollinator takes pollen and nectar from the plant without playing any role in its pollination. ${ }^{7,8}$ Interactions between plants and potential pollinators therefore range from parasitic to obligate mutualistic, with each plant-pollinator interaction a developing relationship, based on how the plant and pollinator adapt to suit each other.

\section{Evolution of plant-pollinator interactions}

Interactions between pollinators and their target plants are usually regarded as being either generalised or specialised. ${ }^{10}$ Generalisation describes an interaction in which a plant has flowers that are morphologically accessible and attractive to many different pollinator species. Specialisation refers to flowers that are sufficiently specialised as to be attractive and/or accessible to only a single type of pollinator. ${ }^{10,11}$ The same can be applied from the pollinator's perspective - that is, the range of plants a pollinator prefers relates to it being generalised or specialised, as discussed below. ${ }^{10,12}$ In some extreme cases, both parties could co-evolve morphologically and behaviourally to allow only one-on-one plant-pollinator interactions, whereby the plant protects access to rewards for its specific pollinator - a feature of, amongst others, many genera in the Orchidaceae. ${ }^{13}$

It has been argued that the formation of specific floral structures in plants is largely driven by means of natural selection from their respective pollinators. ${ }^{9}$ Better pollinator-flower compatibility would, therefore, result in higher selection, through increased fertilisation events of these individuals. The pollinator-plant interaction is important as pollinator or floral adaptations can drive speciation as suggested by the diverse floras of the Cape region, South Africa. ${ }^{14}$ Flowers of angiosperms can gain suites of adaptive traits to make them more suitable to a certain type of pollinator or pollinator guild, also known as floral syndromes. ${ }^{15}$ These floral adaptations or syndromes can lead to reproductive isolation and drive speciation, but isolation and speciation are not necessarily coupled. ${ }^{16}$ It is important to remember that floral syndromes are not an absolute definition of a plant's pollinators but rather a description of how unrelated plants have evolved similar floral traits. ${ }^{16}$

\section{Bees as pollinators}

The most common and invariably important biotic pollinators of angiosperms are bees ${ }^{6}$, as they actively collect pollen as food for themselves and/or their larvae ${ }^{8}$. There is an estimated 25000 bee species in the world of which approximately two-thirds are taxonomically described. ${ }^{9}$ Bees are important pollinators of tropical forest trees ${ }^{17}$ and play an essential role in the pollination of smaller trees, shrubs and herbaceous plants $^{9}$. Many crop plants are bee-pollinated, such as sunflower, tomato, canola, cowpea and coffee. ${ }^{6,18}$

South Africa has high levels of both bee and plant diversity, especially in the southern and western parts of the country that experience predominantly winter rainfall. Approximately $50 \%$ of the bee species known to occur in sub-Saharan Africa are also located in South Africa. ${ }^{19}$ Moreover, $95 \%$ of the bee species found in the winter rainfall region occur only in southern Africa. ${ }^{20}$ The moist, eastern part of the country has also been shown to be diverse in its bee species composition, albeit less so than in the arid western part of South Africa. However, the eastern region still contains a high endemism level of $75 \%{ }^{19,20}$
Although South Africa is particularly rich in pollinators and floristic diversity, relatively few comprehensive studies have investigated pollinator-plant interactions in the country as a whole. In one such study that focused on bees in the arid western region of southern Africa, 16229 plants were visited by 924 species of non-Apis bees, wasps and pollen wasps. ${ }^{2}$ The bees in this study were represented by 420 different species that visited 34 out of the 36 available plant families in the study area. The four plant families most frequently visited by bees were the Fabaceae, Asteraceae, Aizoaceae and Zygophyllaceae. The foraging habits of all the different bee families studied (i.e. the Colletidae, Andrenidae, Halictidae, Mellitidae, Megachilidae and Apidae) ranged from oligolectic (specialised) to narrowly or broadly polylectic (generalised) - although none of the families were nearly as polylectic as Apis mellifera. However, in the Mellitidae, half of the observed species were found to be oligolectic for members of the Wahlenbergia plant genus (Campanulaceae). This work has shed light on the diversity and foraging habits of pollinators in the arid and semi-arid regions of the western part of southern Africa. ${ }^{2}$

No similar regional-scale study of bees in the eastern part of South Africa is currently available. However, there are a few smaller studies of pollinators for specific plant species, for example, in the KwaZulu-Natal midlands in the eastern part of South Africa, Wahlenbergia were visited by halictid species and $A$. mellifera. ${ }^{21}$ It is noteworthy that halictid bees have also been reported to be oligolectic for Wahlenbergia in Australia. ${ }^{22}$ This report indicates a possible adaptation of bees to their locally available flora as was previously reported. ${ }^{23}$ The few available studies, together with the high floristic and bee diversity and endemism in South Africa, highlight the need for further studies into the diversity of bee interactions with plant species - studies that are needed to elucidate floral choice patterns within South African bee populations.

\section{Bee adaptations for foraging}

Bees are active foragers, collecting various substances from flowers. During foraging activity, pollen grains become attached to their bodies. Specialised branched hairs on their bodies trap the pollen grains during the collection of pollen, nectar or oil. ${ }^{24}$ Electrostatic charges on the hairs also aid in the transfer of pollen from anthers to the bee body. In addition, modifications of hairs on the mouthparts, undersides of the heads, or faces of bees all assist in extraction of pollen from flowers. ${ }^{8,24}$ During foraging the pollen is groomed from the insect body into structures used to carry it to the nest. These transport structures, known as scopae, are brushes of hairs located on the hind tarsi of most bee species, or on the bottom of the abdomen as in the Megachilidae. ${ }^{8}$ Structural and behavioural adaptations for the collection of pollen have previously been reviewed in more detail. ${ }^{24}$ When pollen is groomed into transport structures, these pollen grains are generally not available for pollination ${ }^{25}$ as they are tightly packed. Loosely adhered pollen grains on bee bodies are more important in pollination.

\section{Generalist versus specialist interactions}

Bees can exhibit generalist or specialist behaviour in their floral choices for specific requirements. Most bees within the eusocial groups - such as honeybees, bumblebees and most stingless bees - are polylectic in terms of pollen and nectar collection. ${ }^{8}$ They visit plants from a wide variety of taxa that are available for pollen and nectar collection. Polylectic bees still show floral constancy, that is, they make repetitive visits to plants from the same taxon that they have previously visited while the resource is available. ${ }^{26}$ Floral constancy is likely a learned behaviour that increases foraging efficiency during a single trip. ${ }^{8}$ Some bees are more selective as far as pollen is concerned. Solitary bee groups show either polylectic or oligolectic foraging behaviour. When visiting only a single species of plant, bees can be said to be monolectic, but behaviours mostly tend to range from narrowly to broadly oligolectic, with the boundaries between them remaining unclear. ${ }^{27}$ Oligolectic bees still visit flowers from plant taxa other than those from which pollen are collected for other resources, such as nectar and oils. ${ }^{12}$

Floral choices of bee pollinators play an important role in the sustainability of a plant community. According to food web theory, the more complex 
the plant-pollinator interactions are, the less susceptible the plant community is to disturbances or extinction. ${ }^{28}$ If one of the interactions fails for some reason, this interaction would likely be taken over by some other pollinator involved in the complex interaction matrix. In contrast, a plant community with a high level of pollinator specialisation would be markedly more vulnerable to any disturbance in its interactions. Plant communities with high diversity would therefore be able to sustain an increased level of bee specialisation, whereas a low diversity plant community would evolve to increase the complexity level of its plantpollinator interactions. This hypothesis was experimentally verified by increasing plant diversity in a gradient and showing an increase in solitary bee specialisation as plant species richness increased. ${ }^{29}$ Oligolectic bees are also more susceptible to changes in their environment and thus to extinction. Because specialist bees have a more restricted foraging range, their effective population size $\left(\mathrm{N}_{\mathrm{e}}\right)$ and levels of genetic variation are lowered, making these bees and pollination systems vulnerable and in need of protection. ${ }^{30}$

\section{Studying bee-plant interactions}

Plant-pollinator interactions have historically been studied through careful and patient observation. This observation usually involves lengthy field-based experiments ${ }^{2}$ with plant species in a demarcated area studied for a specific time to see which, if any, animals visit the flowers. ${ }^{2,18}$ However, an animal that visits a plant is not necessarily a pollinator of that plant. Even when pollen is transferred to a receptive stigma, genetic incompatibility between pollen and plant may still prevent fertilisation from taking place, as pollen tubes may not germinate, pollen tube growth down the style may be terminated, or pollen may simply be unviable. ${ }^{31}$ Fertilisation could be unsuccessful because the pollen being deposited onto the stigma is from a different plant species. Self-incompatibility also prevents fertilisation by pollen from the same plant. ${ }^{31}$ Laboratory experiments using captive pollinators can also be conducted, especially for confirmation studies, but these studies do not reflect the pollinators' natural environment. ${ }^{32}$

Field-based observation can be followed by determination of the pollen loads on potential pollinators and the assessment of pollination effectiveness, as measured by the degree of fruiting and seed set through examinations of the individual plants visited. ${ }^{33}$ Pollen load determination of any potential pollinator requires capturing the animal in question and the removal of the pollen it carries. The pollen morphology is then carefully analysed (palynology) to identify, or confirm, the plant species from which it originates. Palynology-based identification requires sufficient knowledge of the field and intimate familiarity and expertise with pollen morphological structures, especially of closely related plant species. Furthermore, some form of microscopy is required for visualising the pollen's morphological features used in the identification process, such as scanning electron microscopy or compound light microscopy. ${ }^{31,34}$ These technologies require specialised sample preparation methods, skill to prepare and operate instruments, and experience to best obtain comparative morphological features between samples. Additionally, pollen morphological features of different plant species or genera can be extremely similar, especially if they are closely related, thereby requiring a wide palynology knowledge base to accurately distinguish between these samples. ${ }^{34}$ Mixed pollen samples from closely related species would therefore require a highly skilled and knowledgeable palynologist, usually an expert familiar with the pollen from the area under investigation. The pollen-carrier must also be identified to make accurate inferences, ${ }^{2}$ a function normally performed by different taxonomic specialists in entomology. This process makes plant-pollinator interaction studies time-consuming and highly multidisciplinary, and requires expertise in the fields of taxonomy, botanical reproduction, palynology, entomology and microscopy.

\section{Pollinator declines}

The most well-known bee species is the honeybee, Apis mellifera Linnaeus, and most bee-related research has focused on this species. ${ }^{6,35}$ Honeybee populations have been reported to be declining in certain areas of the world, such as central Europe, the United States of America and Mexico. ${ }^{35,36}$ Although there is as yet no consensus on what may be driving $A$. mellifera population decline, factors such as insecticide use on crops; pests, diseases and predators; a decrease in genetic variation of bee colonies; the effects of climate change; and limitations in the trade of bee colonies may all play a role. ${ }^{35,36}$

In South Africa and some other countries, honeybee numbers are seemingly not declining. This is attributed to beekeeping (apiculture) and the past intentional introduction of numerous alien plant species, which widened the honeybee foraging range. ${ }^{37}$ Honeybee colonies in South Africa were seen to be resilient to most diseases. This view was supported when an outbreak of American foulbrood in 2011 did not cause any major colony losses. ${ }^{38}$ More recently in 2015, however, another American foulbrood outbreak in South Africa reduced the number of colonies in the Western Cape by $40 \%{ }^{39}$

It is not only honeybee populations that have been declining over time. Researchers in Britain and the Netherlands have found a correlation between declines in native bees and declines in the number of outcrossing plant species dependent on these bees. ${ }^{40}$ The native bees in both countries have narrow habitat requirements and produce single broods per year. Honeybee data were specifically excluded, but data for all native species for both countries were included in the analyses. The ultimate cause and direction of the declines could not be determined from the data, but the aforementioned study supports the notion that species reliant on a wider range of interactions within a plant-pollinator system would be more resilient when threatened. ${ }^{40}$

A changing climate, inappropriate land-management and a growing human population have contributed to the reduction of overall biodiversity, including native, wild bee populations across the world..$^{40}$ An important determinant of the maintenance of plant-pollinator interactions is the way land is used and managed. ${ }^{6,41}$ When agriculture is intensified on a piece of land, bee diversity can decline because of fewer opportunities for them to nest, lower foraging diversity and possible insecticide use on crops. ${ }^{6}$ In South Africa's Karoo, all of these factors have been documented to result in a decline of bee and wasp diversity. ${ }^{4}$ Game farming started to replace stock farming in this region and land is often overexploited. Tourism opportunities availed from game farming resulted in the introduction of animal species not normally found in the area, and also no period of rest for the land to recover. In areas where large plots of single cultivated plants (monocultures) are found, such as in the wheat fields and wine lands of the Western Cape, very little of the natural vegetation remains. These areas are also likely sprayed with pesticides. In combination, these factors can cause the complete loss of native bee and wasp communities. ${ }^{4}$

\section{Managing pollinators}

Native honeybees are currently the only pollinators that are being managed in South Africa. The management of honeybee colonies for pollination purposes has several advantages and disadvantages. One major advantage of using honeybees in pollination management is their generalist foraging habits that make them suitable to be used on many different crop species. Like many other bee species, they are nevertheless unable to pollinate all crops. ${ }^{41}$ Additionally, they pack their collected pollen into the corbiculae on their hind legs after moistening it with nectar or honey. This results in limited pollen available for pollination ${ }^{8}$ and renders the honeybee a poorer pollinator when compared to other bee species ${ }^{25}$. African honeybees are also aggressive and care needs to be taken when working with them. ${ }^{41}$ Their susceptibility to pesticides, diseases and parasites also threatens their commerciality ${ }^{35}$ and it is consequently important that pollination management strategies using other native species be explored.

Crop production has increased dramatically over the past decades to meet the demands of growing populations. This growth means that pollinator population sizes are not adequate to deal with the demand. Managed pollinators provide a solution to this problem. It would be best to manage indigenous pollinator populations, such as the honeybee in Africa, to alleviate the problem. In light of some of the inadequacies of honeybees as pollinators, and it being the only group of managed pollinators in South Africa, investigation into the floral choices of native bees could 
identify candidates for management in the place of, or in addition to, honeybee populations. It is possible that an indigenous carpenter bee, Xylocopa scioensis, could be managed for tomato pollination in South Africa, much like the leafcutter bee, Megachile rotundata, is used for alfalfa (lucerne) pollination in North America. ${ }^{42}$ Tomatoes require vibratile ('buzz') pollination, something not effectively achieved by honeybees. This indigenous species could potentially avoid the need to import foreign pollinators as has been proposed for the Western region of South Africa, to aid in the pollination of particularly vibratile pollinated crops. ${ }^{43}$

\section{Effects of Bombus introduction}

The introduction of generalist pollinators, like the honeybee, to provide pollination services to multiple crop species is an economic choice. The honeybee (A. mellifera) naturally occurs throughout Africa, Europe and western Asia, but has been introduced to a significant proportion of the rest of the world as a successful pollinator. ${ }^{22}$ The European bumblebee, Bombus terrestris, is most commonly found throughout Europe but has also recently been introduced into other countries ${ }^{44,45}$, and its effect on the environment is well documented. Suggestions have been made that South Africa would benefit from introducing $B$. terrestris and managing their populations for pollination ${ }^{43}$ as South Africa does not have any native Bombus species.

The impact of the introduction of any alien species into an environment should therefore be carefully considered, as it could be devastating to native ecosystems. This effect was demonstrated with two indigenous subspecies of $A$. mellifera in South Africa: $A$. $m$. capensis and A. m. scutellata. When colonies of $A$. $m$. capensis were moved across the hybrid zone separating these subspecies in the early 1990s, tens of thousands of $A$. $m$. scutelata colonies were lost. ${ }^{46}$ The loss occurred because of the ability of $A$. m. capensis to infest $A$. m. scutelata colonies and then establish a female clonal lineage that parasitises on $A$. $m$. scutellata colonies - a trait unique to $A$. $m$. capensis. These infestations have been shown to only occur when humans transport A. m. capensis colonies into A. m. scutelata's native habitat. ${ }^{47}$

Similarly, since its introduction into foreign habitats, $B$. terrestris has had major effects on native plant and bee populations, both positive and negative. It has been shown to increase pollination overall, but decrease efficiency of pollination in native plants, enhance pollination in weeds, and cause displacement of native pollinators. ${ }^{44}$ It was discovered, by chance, to have invaded Neuquén Province in Argentina during a survey of floral visitors of shrubs. The bees were thought to have entered Argentina from Chile, as extensive studies of natural and museum populations in Argentina did not provide any historical evidence for the presence of $B$. terrestris. ${ }^{45}$ Analysis of the pollen found on the $B$. terrestris individuals showed that they were competing with an indigenous Bombus species for food on seven out of the eight host plants. In Japan, $B$. terrestris was introduced to pollinate crops, but then escaped from greenhouses, became naturalised and has had negative consequences on the native bee populations. ${ }^{48}$ Resource competition between the introduced and native bumblebees was found in the Japanese study. Introduced species also interfered with the reproduction of both native plants and native bumblebees (by interspecies crosses). Additionally, new parasites were introduced to native populations. Native bumblebee populations have been displaced by $B$. terrestris before, ${ }^{49}$ making its invasiveness of great concern. Previously, it has invaded Tasmanian national and urban gardens where it was found foraging on a wide variety of plant types. ${ }^{44}$

Therefore, the use of a foreign pollinator in South Africa should be carefully considered. Native, oligolectic bee species in South Africa would be particularly vulnerable to an introduction of $B$. terrestris, or any other polylectic species, that would be managed for pollination services. So far, permits have not been granted to import $B$. terrestris into South Africa, but in February 2014, Senegal received a shipment of $B$. terrestris colonies from Belgium ${ }^{50}$, signifying the first introduction of this species in sub-Saharan Africa ${ }^{43}$. The preceding evidence clearly indicates the possibility that the bees introduced elsewhere in Africa could spread to South Africa.

\section{Harnessing genetic methods to examine floral choice}

The high species diversity of both plants and pollinators in South Africa makes the traditional methodology for studying plant-pollinator interactions cumbersome and impractical, particularly in projects encompassing many different species of plants and pollinators. Additionally, the few published works in this area suggests limited expertise within this field worldwide. Another approach is therefore needed to investigate these interactions more efficiently. Genetic methods can prove advantageous in revealing the floral choice patterns of native bees in South Africa. Insect taxonomists across the country have built, and are constantly adding to, large collections of native bees sampled from all over the country. Many of these bees have pollen attached to their bodies that can be used to genetically determine the taxa of plants that they visited in the flight before they were collected. Plant species within the country are also currently being collected, identified and barcoded. ${ }^{51}$

\section{DNA barcoding}

DNA barcoding has been successfully used as a diagnostic tool to identify morphologically cryptic species (by comparison to reference libraries) and has highlighted previously unrecognised species, for example various fish and amphipod crustacean species. ${ }^{52-54}$ The genetic barcoding of a specimen involves the amplification of a DNA region that has a higher level of interspecific variation and limited intraspecific divergence. Gene regions used in barcoding should also provide a DNA target that can be easily amplified across many taxa using universal primers. ${ }^{52,55}$

The application of DNA barcoding to identify pollen has only recently been developed. In the last 2 years, research publications utilising barcoding in palynology have increased. ${ }^{56-61}$ The use of next-generation sequencing (NGS) in identifying mixed pollen samples (pollen metabarcoding) has recently become possible, with a full laboratory protocol and bioinformatics analysis pipeline published. ${ }^{61}$

\section{Pollen as a template for genetic studies}

How pollen is collected can impact the success of downstream molecular applications. When sampling pollen from hives, nests, or even honey, sufficient sample quantities are usually available for processing. ${ }^{57,58,61,62}$ Conversely, when sampling pollen directly from pollinators, specimens may have only very limited pollen grains captured on their bodies. Small sample quantities may limit and complicate all further laboratory steps. The physical structure of pollen can also be problematic when used as a template. Pollen has an extremely hardy outer wall to protect it from various environmental factors, and this wall could influence DNA extraction and other processes ${ }^{63}$ Different methods are currently used to extract DNA from pollen, but most include a step to disrupt the tough pollen exine. ${ }^{57-59} \mathrm{~A}$ standardised DNA extraction method for pollen barcoding purposes would greatly aid in the comparability among studies. ${ }^{56}$

Using a NGS approach for plant-pollinator interaction studies allows the collection and barcoding of pollen, even if only a few pollen grains are available. Pollinator specimens can therefore be used as pollen sources. When bees from a natural collection are to be used as a pollen source, some factors need to be kept in mind. Bees might have extremely limited quantities of pollen captured on their bodies, and DNA extraction and all subsequent steps should be optimised for use with low starting DNA concentrations in mind. The manner in which the collection has been maintained is also of primary concern. It is well known that bees collect fungi together with pollen ${ }^{64}$, but a collection kept in suboptimal conditions would see additional fungal and bacterial growth ${ }^{65}$. Depending on the research question, barcoding gene regions can be selected to amplify more than just plant DNA from pollen samples.

\section{Amplifying DNA from pollen samples}

The barcoding principle was first applied to animal groups using the mitochondrial cytochrome $c$ oxidase I gene $(\mathrm{COI}) .^{52}$ In plants, the mitochondrial gene variation is not as great between species as in 
animals thus making the use of the $\mathrm{COI}$ barcode region ineffective as a barcode within the Plant Kingdom. Many studies have been done to search for a suite of barcode markers for use in land plants, with varied outcomes and numerous suggestions of genes to target. ${ }^{66,67}$ The focus has mainly been on the plastid genome, with ribulose-1,5-biphosphate carboxylase oxygenase $(r b c L)$ and maturase $\mathrm{K}$ (matK) being the most studied genes and, at first glance, the most informative. The Consortium for the Barcode of Life Plant Working Group was established to develop all aspects with regard to plant barcoding. They have suggested the use of $r b c L$ and matK as the standard barcode for plants ${ }^{66}$ after evaluating the success of combinations of coding regions (matK, $r b c L, r p o B$ and rpoC1) and non-coding regions (atpF-atpH, trnH-psbA, and psbK$p s b /)$. The internal transcribed spacer (ITS) region of the nuclear genome has been suggested as an additional region to barcode, with several of the plastid genes added to increase identification success. ${ }^{68}$

However, the plastid genome is usually uniparentally inherited; and amplifying plastid DNA could potentially present a problem when evaluating pollen from plants with only maternal plastid inheritance. ${ }^{69}$ When plastids are exclusively maternally inherited, the ITS barcode could be invaluable in identifying the pollen parent plant as pollen contains two sperm cells which contain the nuclear genome of the plant.70,71 Sometimes organellar DNA is biparentally inherited and some plastid leakage from the non-contributing parent can also occur. ${ }^{69}$

\section{PCR and sequencing}

Sequencing pollen DNA has initially been done directly from the PCR template by traditional Sanger sequencing. A study on Hawaiian Hylaeus bees investigated the pollen composition in the bees' guts to determine their pollen foraging behaviour. ${ }^{72}$ ITS barcodes were sequenced for samples that were preserved in $100 \%$ ethanol post-collection and the $28 \mathrm{~S}$ ribosomal RNA region for samples preserved in $70 \%$ ethanol. Using Sanger sequencing, most pollen samples could only be identified to one plant species, but in two samples pollen belonging to two species could be identified. For mixed pollen samples, PCR products have been cloned and subsequently Sanger sequenced. ${ }^{62,73}$ In this approach, a number of clones are picked and sequenced prior to identification against a reference database. Sequencing clones of pollen found in multiflower honey produced identifications for between 12 and 15 taxa per sample and 38 taxa overall 62 , and pollen from honeybee pollen pellets collected from hives produced between 21 and 31 taxa per sample and 52 taxa overall ${ }^{73}$. Pollen identifications were made using the Basic Local Alignment Search Tool (BLAST) available for searching GenBank, which provides a best-hit similarity method of analysis. ${ }^{74}$ However, using a cloning approach to obtain single identifiable barcodes from a mixed sample with a number of unknown species, is time consuming and expensive, with no known way to confirm that all the species have been sequenced successfully.

NGS has made it possible to process many samples simultaneously as a result of the parallel nature of the technology. It is hence much more cost-effective to sequence mixed-origin samples on an NGS platform. ${ }^{75}$ Each PCR strand is sequenced separately in NGS and this eliminates the need for prior microscopic sorting or cloning of mixed pollen samples. Studies published recently in the pollen barcoding field have combined barcoding with NGS as the preferred sequencing method. ${ }^{57-61}$ For example, metabarcoding was used to investigate the floral composition of honey samples in commercial ${ }^{76}$ and domestic beekeeper-provided honeys ${ }^{57}$. A larger region of the same barcode as was used in metabarcoding commercial honeys ${ }^{76}$ - the chloroplast trnL (UAA) intron region - was used to test the efficiency of NGS in identifying the plant origins of airborne pollen ${ }^{59}$. A chloroplast gene was also used as barcode in the study on beekeeper-provided honeys ${ }^{57}$, whereas several others ${ }^{58,60,61}$ were successful using a nuclear region for pollen identification. Different sequencing platforms have been used for pollen metabarcoding; these platforms are summarised in Table 1 together with the particular study's application in the field and choice of genetic barcode marker.
Table 1: A comparison of the recently published pollen metabarcoding studies, focusing on the application of the study, the barcode region selected and the next-generation sequencing platform used in the study

\begin{tabular}{|c|c|c|}
\hline Pollen metabarcoding application & $\begin{array}{l}\text { Barcode } \\
\text { region }\end{array}$ & $\begin{array}{l}\text { Next-generation } \\
\text { sequencing platform }\end{array}$ \\
\hline Aeroallergen monitoring 59 & $\operatorname{trnL}$ & Ion Torrent PGM \\
\hline Provenance monitoring ${ }^{60}$ & ITS2 & Illumina MiSeq \\
\hline Provenance monitoring ${ }^{58}$ & ITS2 & Roche 454 GS junior \\
\hline Provenance monitoring ${ }^{61}$ & ITS2 & Illumina MiSeq \\
\hline Food quality and provenance monitoring ${ }^{57}$ & $r b c L$ & Roche 454 GS FLX \\
\hline Food quality and provenance monitoring ${ }^{76}$ & $\operatorname{trnL}$ & Roche 454 GS 20 \\
\hline
\end{tabular}

Multiplexed samples need a way to be separated post-sequencing. Adding unique sequence indexes to the sequencing adapters in NGS systems allows this to be done bioinformatically. ${ }^{61}$ Various indexing methods have also been successfully used, with dual indexing of PCR products by far the most cost-effective as it allows for a higher degree of multiplexing. Illumina has published a workflow for $16 \mathrm{~S}$ metagenomics that adds overhang adapters to gene-specific PCR primers, from which dual-indexing can be done directly with the Nextera ${ }^{\circledR}$ XT (Illumina Part \#15044223 Rev. B) indexing PCR. This protocol can be adapted for use in any metagenomic application, making it ideal for metabarcoding of pollen.

\section{Bioinformatics}

The incorporation of NGS in the barcoding process produces considerable amounts of data. Bioinformatic pipelines catering to the specific metabarcoding needs of pollen analysis are essential to provide reliable identifications using sequence reference databases. Sequence similarity (or best-hit) approaches ${ }^{74}$ have long been in use, but suffer from some drawbacks. Heuristic searches on local alignments are performed, and a value is given of the probability that another equally good hit will be found by chance. This value is not comparable to a confidence score and relates only to the local alignment, not the taxonomic assignment of the sequence. ${ }^{76,77}$ Other software available for bacterial taxonomy assignments use classifiers, such as the Ribosomal Database Project Classifier $^{78}$ and the UTAX command in USEARCH (currently not published; http://www.drive5.com/usearch/manual/utax_algo.html) and these tend to perform better than best-hit approaches. Classifiers rely on the assignment of information in a hierarchical manner to provide taxonomic classifications together with a confidence score. Incorrect assignments can still be made when classifiers are trained on incomplete or incorrect sequence reference databases. Recently, a complete bioinformatics pipeline has been published for ITS $2^{61}$, providing much needed guidance to researchers in the field. Standardised bioinformatics methods still need to be developed so that data can be easily analysed across different studies.

The reliable use of barcoding in species identification requires highquality sequence databases that connect specific species to their DNA barcodes and that hierarchically connect these species taxonomically. These features are particularly important when mixed-species pollen, such as that sampled from a bee's body, is being assigned to its taxonomic origin during analysis. Additionally, a database is required for each barcode region used, with the availability of barcode sequences for these databases dependent on the usage of the DNA region within the taxon under investigation. Most sequence databases are comprised of sequences obtained from publicly available databases, such as GenBank at the National Center for Biotechnology Information (NCBI). This scenario is not ideal, as misidentified entries could be present and often the relevant barcode markers are not available in these public databases, thereby resulting in gaps for the gene region of interest in the barcode reference database. Additionally, incomplete barcoding of plant 
species within a region further compounds correct identifications. Pollen samples will subsequently be mismatched to available sequences in the reference database or left unidentified. Some sequences are available in databases that undergo quality checks, such as the ITS2-Database. ${ }^{79}$ Plant data contained in the Barcode of Life Database Systems (BOLD; www.boldsystems.org ${ }^{80}$ ) are all from $r b c L$ and matK, the two proposed plant plastid barcodes. These sequences are submitted by researchers and must conform to certain standards to be accepted. The available ITS2-Database has also recently been expanded nearly 2.5 times for plants. ${ }^{61}$ Curated databases provide higher confidence in the underlying sequence data, whereas sequences in NCBI are often taxonomically misclassified, but sometimes represent the only available entry for a particular species. This limitation could lead to the underestimation of within-species diversity as a result of recent speciation. ${ }^{81}$ Bioinformatics methods applied to barcoding sequence data are consequently a crucial part of producing reliable pollen identifications.

\section{Conclusion}

Given South Africa's rich flowering plant and bee diversity, the immense economic significance of pollination for agriculture, and the threats of climate change and poor land management on the country's biodiversity, investigations into plant-pollinator relationships are vital. Floral choice in bees gives a good indication of which plants they likely pollinate. Oligolectic bees are more vulnerable to upsets in their relationships with plants. As it has been suggested that the Succulent Karoo Biome in the western part of South Africa contains many oligolectic species, this is a key region of interest for study. Should bumblebees be introduced to this area, as suggested previously, much of the bee biodiversity of South Africa could be at stake. The identification of pollen origins is important in understanding the floral choices of bees. Many advances have been made in recent years in molecular pollen identification. DNA metabarcoding can provide accurate taxonomic identifications of pollen origins when compared to comprehensive sequence databases of carefully selected barcode gene regions. However, the lack of barcoding information for the bulk of the South African flora is a major stumbling block still to be overcome. Pollen from both honeybees and their honey, and solitary bees, has successfully been identified using this technique. DNA metabarcoding should prove instrumental in the exploration of floral choice in South African bees.

\section{Acknowledgements}

We thank the National Research Foundation of South Africa (grant 95649) and the Belgian Directorate-General for Development Cooperation, partim GTI for funding the research. A.G. also thanks the South African Department of Science and Technology/National Research Foundation Professional Development Programme (99781), the Biotechnology Platform at the Agricultural Research Council, and the University of KwaZulu-Natal for support. We also thank the anonymous reviewers who made extremely useful comments which lead to the improvement of our manuscript.

\section{Authors' contributions}

Z.H.S., C.E. and S.W.M. were the project leaders; A.G., Z.H.S., C.E. and S.W.M. were responsible for project design; A.G., Z.H.S., C.E. and S.W.M. made conceptual contributions; and Z.H.S., C.E. and S.W.M. supervised A.G. in her PhD studies. A.G. wrote and revised the manuscript, and Z.H.S., C.E. and S.W.M. provided critical reviews of the manuscript.

\section{References}

1. Mittermeier RA, Turner WR, Larsen FW, Brooks TM, Gascon C. Global biodiversity conservation: The critical role of hotspots. In: Zachos FE, Habel JC, editors. Biodiversity hotspots. Heidelberg: Springer; 2011. p. 3-22. https://doi.org/10.1007/978-3-642-20992-5_1

2. Gess SK, Gess FW. A comparative overview of flower visiting by non-Apis bees in the semi-arid to arid areas of southern Africa. J Kans Entomol Soc. 2004;77(4):602-618. http://dx.doi.org/10.2317/E7.1

3. South African Department of Environmental Affairs. Land. In: 2nd South Africa Environment Outlook: A report on the state of the environment. Pretoria: Department of Environmental Affairs; 2012. p. 87-105.
4. Gess SK, Gess FW. Wasps and bees in southern Africa. Pretoria: South African National Biodiversity Institute; 2014.

5. Losey JE, Vaughan M. The economic value of ecological services provided by insects. BioScience. 2006;56(4):311-323. http://dx.doi.org/10.1641/00063568(2006)56[311:TEVOES]2.0.C0;2

6. Klein A-M, Vaissiere BE, Cane JH, Steffan-Dewenter I, Cunningham SA, Kremen $\mathrm{C}$, et al. Importance of pollinators in changing landscapes for world crops. Proc R Soc B Biol Sci. 2007;274(1608):303-313. http://dx.doi. org/10.1098/rspb.2006.3721

7. Kearns CA, Inouye DW, Waser NM. Endangered mutualisms: The conservation of plant-pollinator interactions. Annu Rev Ecol Syst. 1998;29:83-112. http:// dx.doi.org/10.1146/annurev.ecolsys.29.1.83

8. Michener CD. The bees of the world. 2nd ed. Baltimore: Johns Hopkins University Press; 2000.

9. Johnson SD. The pollination niche and its role in the diversification and maintenance of the southern African flora. Philos Trans R Soc B Biol Sci. 2010;365(1539):499-516. http://dx.doi.org/10.1098/rstb.2009.0243

10. Minckley RL, Cane JH, Kervin L. Origins and ecological consequences of pollen specialization among desert bees. Proc R Soc Lond B Biol Sci. 2000;267(1440):265-271. http://dx.doi.org/10.1098/rspb.2000.0996

11. Padyšáková $E$, Bartoš $M$, Tropek $R$, Janeček Š. Generalization versus specialization in pollination systems: Visitors, thieves, and pollinators of Hypoestes aristata (Acanthaceae). PLoS ONE. 2013;8(4), e59299, 8 pages. http://dx.doi.org/10.1371/journal.pone.0059299

12. Bosch J, Martín González AM, Rodrigo A, Navarro D. Plant-pollinator networks: Adding the pollinator's perspective. Ecol Lett. 2009;12(5):409419. http://dx.doi.org/10.1111/j.1461-0248.2009.01296.x

13. Hetherington-Rauth MC, Ramírez SR. Evolutionary trends and specialization in the euglossine bee-pollinated orchid genus Gongora. Ann Mo Bot Gard. 2015;100(4):271-299. http://dx.doi.org/10.3417/2014035

14. Johnson SD. Pollination, adaptation and speciation models in the Cape flora of South Africa. Taxon. 1996;45(1):59-66. http://dx.doi.org/10.2307/1222585

15. De Merxem DG, Borremans B, De Jäger ML, Johnson T, Jooste M, Ros P, et al. The importance of flower visitors not predicted by floral syndromes. S Afr J Bot. 2009;75(4):660-667. http://dx.doi.org/10.1016/j.sajb.2009.08.002

16. Johnson SD, Steiner KE. Generalization versus specialization in plant pollination systems. Trends Ecol Evol. 2000;15(4):140-143. http://dx.doi. org/10.1016/S0169-5347(99)01811-X

17. Bawa KS. Plant-pollinator interactions in tropical rain forests. Annu Rev Ecol Syst. 1990;21:399-422. http://dx.doi.org/10.1146/annurev. es.21.110190.002151

18. Kwapong PK, Danquah POA, Asare AT. Insect floral visitors of cowpea (Vigna unguiculata L.). Ann Biol Res. 2013;4(4):12-18.

19. Kuhlmann M. Patterns of diversity, endemism and distribution of bees (Insecta: Hymenoptera: Anthophila) in southern Africa. S Afr J Bot. 2009;75(4):726738. http://dx.doi.org/10.1016/j.sajb.2009.06.016

20. Eardley CD. Diversity and endemism of southern African bees. Plant Protection News. 1989 Dec;18:1-2.

21. Welsford MR, Johnson SD. Solitary and social bees as pollinators of Wahlenbergia (Campanulaceae): Single-visit effectiveness, overnight sheltering and responses to flower colour. Arthropod-Plant Interact. 2012;6(1):1-14. http://dx.doi.org/10.1007/s11829-011-9149-0

22. Goulson D. Effects of introduced bees of native ecosystems. Annu Rev Ecol Syst. 2003;34:1-26. http://dx.doi.org/10.1146/annurev. ecolsys.34.011802.132355

23. Ginsberg HS. Historical development of bee foraging patterns in central New York State. Psyche (Stuttg). 1981;88(3-4):337-346. http://dx.doi. org/10.1155/1981/29040

24. Thorp RW. The collection of pollen by bees. Plant Syst Evol. 2000;222:211223. http://dx.doi.org/10.1007/BF00984103

25. Westerkamp C. Honeybees are poor pollinators - why? Plant Syst Evol. 1991;177(1-2):71-75. http://dx.doi.org/10.1007/BF00937827 
26. Wilson P, Stine M. Floral constancy in bumble bees: Handling efficiency or perceptual conditioning? Oecologia. 1996;106(4):493-499. http://dx.doi. org/10.1007/BF00329707

27. Linsley EG. The ecology of solitary bees. Vol. 27. Berkeley, CA: University of California; 1958

28. Melián CJ, Bascompte J. Food web structure and habitat loss. Ecol Lett. 2002;5(1):37-46. http://dx.doi.org/10.1046/j.1461-0248.2002.00280.x

29. Ebeling A, Klein A-M, Tscharntke T. Plant-flower visitor interaction webs: Temporal stability and pollinator specialization increases along an experimental plant diversity gradient. Basic Appl Ecol. 2011;12(4):300-309. http://dx.doi. org/10.1016/j.baae.2011.04.005

30. Packer L, Zayed A, Grixti JC, Ruz L, Owen RE, Vivallo F, et al. Conservation genetics of potentially endangered mutualisms: Reduced levels of genetic variation in specialist versus generalist bees. Conserv Biol. 2005;19(1):195202. http://dx.doi.org/10.1111/j.1523-1739.2005.00601.x

31. Dafni A. Pollination ecology: A practical approach. Oxford: Oxford University Press; 1992.

32. Harder LD. Choice of individual flowers by bumble bees: Interaction of morphology, time and energy. Behaviour. 1988;104(1/2):60-77. http:// dx.doi.org/10.1163/156853988X00601

33. Klein A-M, Steffan-Dewenter I, Tscharntke T. Fruit set of highland coffee increases with the diversity of pollinating bees. Proc R Soc B Biol Sci. 2003;270(1518):955-961. http://dx.doi.org/10.1098/rspb.2002.2306

34. Rahl M. Microscopic identification and purity determination of pollen grains. In: Jones MG, Lympany P, editors. Allergy methods and protocols. Totowa, NJ: Humana Press; 2008. https://doi.org/10.1007/978-1-59745-366-0_22

35. VanEngelsdorp D, Meixner MD. A historical review of managed honey bee populations in Europe and the United States and the factors that may affect them. J Invertebr Pathol. 2010;103:S80-S95. http://dx.doi.org/10.1016/j. jip.2009.06.011

36. Goulson D, Nicholls E, Botías C, Rotheray EL. Bee declines driven by combined stress from parasites, pesticides, and lack of flowers. Science. 2015;347(6229), Art. \#1255957. http://dx.doi.org/10.1126/ science. 1255957

37. Jaffé R, Dietemann V, Allsopp MH, Costa C, Crewe RM, Dall'Olio R, et al. Estimating the density of honeybee colonies across their natural range to fill the gap in pollinator decline censuses. Conserv Biol. 2010;24(2):583-593. http://dx.doi.org/10.1111/j.1523-1739.2009.01331.x

38. Human H, Pirk CWW, Crewe RM, Dietemann V. The honeybee disease American foulbrood - An African perspective. Afr Entomol. 2011;19(3):551557. http://dx.doi.org/10.4001/003.019.0301

39. Kings S. Honeybee crisis catches SA off-guard. Mail \& Guardian. 2015 April 17 [cited 2016 Jun 01]. Available from: http://mg.co.za/article/2015-04-16honeybee-crisis-catches-sa-off-guard

40. Biesmeijer JC, Roberts SPM, Reemer M, Ohlemüller R, Edwards M, Peeters T, et al. Parallel declines in pollinators and insect-pollinated plants in Britain and the Netherlands. Science. 2006;313:351-353. http://dx.doi.org/10.1126/ science. 1129551

41. Kearns CA, Inouye DW. Pollinators, flowering plants, and conservation biology. BioScience. 1997;47(5):297-307. http://dx.doi.org/10.2307/1313191

42. Pitts-Singer TL, Cane JH. The alfalfa leafcutting bee, Megachile rotundata: The world's most intensively managed solitary bee. Annu Rev Entomol. 2011;56(1):221-237. http://dx.doi.org/10.1146/annurevento-120709-144836

43. Rodger J, Donaldson J, Eardley C, Pauw A, Johnson S. SA should put bumblebees to flight. Farmer's Weekly. 2013 [updated 2014 Jul 09; cited 2016 Mar 12]. Available from: http://www.farmersweekly.co.za/article. aspx?id=40333\&h=SA-should-put-bumblebees-to-flight

44. Hingston AB, Marsden-Smedley J, Driscoll DA, Corbett S, Fenton J, Anderson $\mathrm{R}$, et al. Extent of invasion of Tasmanian native vegetation by the exotic bumblebee Bombus terrestris (Apoidea: Apidae). Austral Ecol. 2002;27(2):162-172. http://dx.doi.org/10.1046/j.1442-9993.2002.01179.x

45. Torretta JP, Medan D, Abrahamovich AH. First record of the invasive bumblebee Bombus terrestris (L.)(Hymenoptera, Apidae) in Argentina. Trans Am Entomol Soc. 2006;132:285-289. http://dx.doi.org/10.3157/00028320(2006)132[285:FROTIB]2.0.C0;2
46. Byatt MA, Chapman NC, Latty T, Oldroyd BP. The genetic consequences of the anthropogenic movement of social bees. Insectes Sociaux. 2016;63(1):1524. https://doi.org/10.1007/s00040-015-0441-3

47. Beekman M, Allsopp MH, Wossler TC, Oldroyd BP. Factors affecting the dynamics of the honeybee (Apis mellifera) hybrid zone of South Africa. Heredity. 2008;100(1):13-18. http://dx.doi.org/10.1038/sj.hdy.6801058

48. Goka K. Introduction to the special feature for ecological risk assessment of introduced bumblebees: Status of the European bumblebee, Bombus terrestris, in Japan as a beneficial pollinator and an invasive alien species. Appl Entomol Zool. 2010;45(1):1-6. http://dx.doi.org/10.1303/aez.2010.1

49. Inoue MN, Yokoyama J, Washitani I. Displacement of Japanese native bumblebees by the recently introduced Bombus terrestris (L.) (Hymenoptera: Apidae). J Insect Conserv. 2008;12(2):135-146. http://dx.doi.org/10.1007/ s10841-007-9071-z

50. Siegmund $\mathrm{H}$. Brussels airlines cargo welcomes 16 queen bees aboard. CargoForwarder Global. 2014 March 03 [cited 2016 Mar 12]. Available from: $\quad$ http://www.cargoforwarder.eu/2014/03/03/brussels-airlines-cargowelcomes-16-queen-bees-aboard/

51. Lahaye R, Van der Bank M, Bogarin D, Warner J, Pupulin F, Gigot G, et al. DNA barcoding the floras of biodiversity hotspots. Proc Natl Acad Sci USA 2008;105(8):2923-2928. https://doi.org/10.1073/pnas.0709936105

52. Hebert PDN, Cywinska A, Ball SL, deWaard JR. Biological identifications through DNA barcodes. Proc R Soc B Biol Sci. 2003;270(1512):313-321. http://dx.doi.org/10.1098/rspb.2002.2218

53. Ward RD, Zemlak TS, Innes BH, Last PR, Hebert PDN. DNA barcoding Australia's fish species. Philos Trans R Soc B Biol Sci. 2005;360(1462):18471857. http://dx.doi.org/10.1098/rstb.2005.1716

54. Witt JDS, Threloff DL, Hebert PDN. DNA barcoding reveals extraordinary cryptic diversity in an amphipod genus: Implications for desert spring conservation. Mol Ecol. 2006;15(10):3073-3082. http://dx.doi.org/10.1111/ j.1365-294X.2006.02999.x

55. Moritz C, Cicero C. DNA barcoding: Promise and pitfalls. PLoS Biol. 2004;2(10), e354, 3 pages. http://dx.doi.org/10.1371/journal.pbio.0020354

56. Bell K, De Vere N, Keller A, Richardson R, Gous A, Burgess K, et al. Pollen DNA barcoding: Current applications and future prospects. Genome. 2016;59:629-640. http://dx.doi.org/10.1139/gen-2015-0200

57. Hawkins J, De Vere N, Griffith A, Ford CR, Allainguillaume J, Hegarty MJ, et al. Using DNA metabarcoding to identify the floral composition of honey: A new tool for investigating honey bee foraging preferences. PLoS ONE. 2015;10(8), e0134735, 20 pages. http://dx.doi.org/10.1371/journal.pone.0134735

58. Keller A, Danner N, Grimmer G, Ankenbrand M, Von der Ohe K, Von der Ohe $W$, et al. Evaluating multiplexed next-generation sequencing as a method in palynology for mixed pollen samples. Plant Biol. 2015;17(2):558-566. http:// dx.doi.org/10.1111/plb.12251

59. Kraaijeveld K, De Weger LA, Ventayol García M, Buermans H, Frank J, Hiemstra PS, et al. Efficient and sensitive identification and quantification of airborne pollen using next-generation DNA sequencing. Mol Ecol Resour. 2015;15(1):8-16. http://dx.doi.org/10.1111/1755-0998.12288

60. Richardson RT, Lin C-H, Quijia J0, Riusech NS, Goodell K, Johnson RM. Rank-based characterization of pollen assemblages collected by honey bees using a multi-locus metabarcoding approach. Appl Plant Sci. 2015;3(11), 1500043, 9 pages. http://dx.doi.org/10.3732/apps.1500043

61. Sickel W, Ankenbrand MJ, Grimmer G, Holzschuh A, Härtel S, Lanzen J, et al Increased efficiency in identifying mixed pollen samples by meta-barcoding with a dual-indexing approach. BMC Ecol. 2015;15(1), Art. \#20, 9 pages. http://dx.doi.org/10.1186/s12898-015-0051-y

62. Bruni I, Galimberti A, Caridi L, Scaccabarozzi D, De Mattia F, Casiraghi M, et al. A DNA barcoding approach to identify plant species in multiflower honey. Food Chem. 2015;170:308-315. http://dx.doi.org/10.1016/j. foodchem.2014.08.060

63. Edlund AF. Pollen and stigma structure and function: The role of diversity in pollination. Plant Cell. 2004;16:S84-S97. http://dx.doi.org/10.1105/ tpc.015800

64. Eltz T, Brühl CA, Görke C. Collection of mold (Rhizopus sp.) spores in lieu of pollen by the stingless bee Trigona collina. Insectes Sociaux. 2002;49(1):2830. http://dx.doi.org/10.1007/s00040-002-8274-2 
65. Merritt J. Mold: Prevention of growth in museum collections. Conserve 0 Gram. 2007;3/4:1-5.

66. Consortium for the Barcode of Life Plant Working Group. A DNA barcode for land plants. Proc Natl Acad Sci USA. 2009;106(31):12794-12797. http:// dx.doi.org/10.1073/pnas.0905845106

67. Kress WJ, Erickson DL. A two-locus global DNA barcode for land plants: The coding $r b c L$ gene complements the non-coding $t r n H-p s b A$ spacer region. PLoS ONE. 2007;2(6), e508, 10 pages. http://dx.doi.org/10.1371/journal. pone.0000508

68. Yao H, Song J, Liu C, Luo K, Han J, Li Y, et al. Use of ITS2 region as the universal DNA barcode for plants and animals. PLOS ONE. 2010;5(10), e13102, 9 pages. http://dx.doi.org/10.1371/journal.pone.0013102

69. Corriveau JL, Goff LJ, Coleman AW. Plastid DNA is not detectable in the male gametes and pollen tubes of an angiosperm (Antirrhinum majus) that is maternal for plastid inheritance. Curr Genet. 1990;17(5):439-444. http:// dx.doi.org/10.1007/BF00334525

70. McCue AD, Cresti M, Feijo JA, Slotkin RK. Cytoplasmic connection of sperm cells to the pollen vegetative cell nucleus: potential roles of the male germ unit revisited. J Exp Bot. 2011;62(5):1621-1631. http://dx.doi.org/10.1093/ jxb/err032

71. Nagata N, Saito C, Sakai A, Kuroiwa H, Kuroiwa T. The selective increase or decrease of organellar DNA in generative cells just after pollen mitosis one controls cytoplasmic inheritance. Planta. 1999;209(1):53-65. http://dx.doi. org/10.1007/s004250050606

72. Wilson EE, Sidhu CS, LeVan KE, Holway DA. Pollen foraging behaviour of solitary Hawaiian bees revealed through molecular pollen analysis. Mol Ecol. 2010;19(21):4823-4829. http://dx.doi.org/10.1111/j.1365294X.2010.04849.x
73. Galimberti A, De Mattia F, Bruni I, Scaccabarozzi D, Sandionigi A, Barbuto M, et al. A DNA barcoding approach to characterize pollen collected by honeybees. PLOS 0NE. 2014;9(10), e109363, 13 pages. https://doi.org/10.1371/journal. pone.0109363

74. Altschul SF, Gish W, Miller W, Myers EW, Lipman DJ. Basic local alignment search tool. J Mol Biol. 1990;215(3):403-410. http://dx.doi.org/10.1016/ S0022-2836(05)80360-2

75. Liu L, Li Y, Li S, Hu N, He Y, Pong R, et al. Comparison of next-generation sequencing systems. J Biomed Biotechnol. 2012;2012, Art. \#251364, 11 pages. http://dx.doi.org/10.1155/2012/251364

76. Valentini A, Miquel C, Taberlet P. DNA barcoding for honey biodiversity. Diversity. 2010;2(4):610-617. http://dx.doi.org/10.3390/d2040610

77. Munch K, Boomsma W, Huelsenbeck J, Willerslev E, Nielsen R. Statistical assignment of DNA sequences using Bayesian phylogenetics. Syst Biol. 2008;57(5):750-757. http://dx.doi.org/10.1080/10635150802422316

78. Wang Q, Garrity GM, Tiedje JM, Cole JR. Naive Bayesian classifier for rapid assignment of rRNA sequences into the new bacterial taxonomy. Appl Environ Microbiol. 2007;73(16):5261-5267. http://dx.doi.org/10.1128/AEM.0006207

79. Keller A, Schleicher T, Schultz J, Müller T, Dandekar T, Wolf M. 5.8S-28S rRNA interaction and HMM-based ITS2 annotation. Gene. 2009;430(1-2):50-57. http://dx.doi.org/10.1016/j.gene.2008.10.012

80. Ratnasingham S, Hebert PD. BOLD: The Barcode of Life Data System (http:// www. barcodinglife. org). Mol Ecol Notes. 2007;7(3):355-364. http://dx.doi. org/10.1111/j.1471-8286.2007.01678.x

81. Sandionigi A, Galimberti A, Labra M, Ferri E, Panunzi E, De Mattia F, et al. Analytical approaches for DNA barcoding data - How to find a way for plants? Plant Biosyst. 2012;146(4):805-813. http://dx.doi.org/10.1080/11263504.2 012.740084 